\title{
$\widehat{A}$ Madridge \\ madridge Journal of Cancer Study \& Research \\ Interconnecting Scientific World
}

Research Article

Open Access

\section{Predictive value of Serum IL-6 level and CRP titer in Determining the need for Antifungal Therapy in Pediatric Patients with Febrile Neutropenia}

\author{
Shahla Ansari ${ }^{1}$, Tahereh Rostami ${ }^{2 *}$ and Azadeh Kiumarsi ${ }^{2}$ \\ ${ }^{1}$ Department of Hematology and Oncology, St Ali-Asghar Hospital, Iran University of Medical Sciences, Iran \\ ${ }^{2}$ Hematology, Oncology and Hematopoietic Stem Cell Transplantation Research Center, Shariati Hospital, Tehran University of \\ Medical Sciences, Iran
}

\section{Article Info \\ *Corresponding author: \\ Dr. Tahereh Rostami \\ Hematology, Oncology and Hematopoietic \\ Stem Cell Transplantation Research Center \\ Shariati Hospital \\ North Kargar St \\ Tehran \\ Iran \\ Tel: 00982184902687 \\ E-mail: trostami@sina.tums.ac.ir}

Received: June 30, 2018

Accepted: July 22, 2018

Published: July 27, 2018

Citation: Ansari S, Rostami T, Kiumarsi A. Predictive value of Serum IL-6 level and CRP titer in Determining the need for Antifungal Therapy in Pediatric Patients with Febrile Neutropenia. Madridge J Cancer Stud Res. 2018; 2(1): 55-58.

doi: $10.18689 / \mathrm{mjcsr}-1000107$

\section{Copyright: (c) 2018 The Author(s). This work is licensed under a Creative Commons Attribution 4.0 International License, which permits unrestricted use, distribution, and reproduction in any medium, provided the original work is properly cited.}

Published by Madridge Publishers

\begin{abstract}
Background: A suitable biomarker for early prediction of unfavourable course in pediatric oncologic patients with febrile neutropenia is still needed. The objective of this study was to assess the predictive value of serum interleukin-6 (IL-6) level and C-reactive protein (CRP) titer in evaluating the need for antifungal therapy for children with fever and neutropenia during cancer chemotherapy.
\end{abstract}

Methods and Materials: In this comparative cross-sectional study, 60 episodes of febrile neutropenia in 49 childhood cancer patients were enrolled. Serum samples were collected at presentation after confirmation of febrile neutropenia and also in their third day of admission.

Results: The positive predictive value of serum IL- 6 level and CRP titer on the first day of admission for predicting the need for antifungal therapy was $55.6 \%$ versus $70.8 \%$. The positive predictive value of serum IL- 6 level and CRP titer on the third day of admission for predicting the need for antifungal therapy were $60 \%$ versus $75 \%$.

Conclusions: Altogether, our data suggest that CRP titer as an available and low cost test, could have a good predictive value in determining the need for antifungal therapy in a febrile neutropenic episode.

Keywords: interleukin-6 (IL-6), C-reactive protein (CRP), febrile neutropenia.

\section{Introduction}

Infectious complications during neutropenic phase after chemotherapy in children with cancer are significant cause of morbidity and mortality. In most cases, fever is an early serious symptom of infection. Traditional management for febrile neutropenia (FN) involved inpatient admission and rapid initiation of empiric broad-spectrum intravenous (IV) antibiotics until recovery of the absolute neutrophil count (ANC). This approach has dramatically reduced the mortality of pediatric $\mathrm{FN}$ to be about $2 \%$ [1]. However, at the time of fever presentation in a neutropenic child, discrimination between serious and less significant infections seems to be difficult [2, 3]. In severely neutropenic patients, lack of local signs of inflammation makes it difficult to diagnose the type of infection [4]. On the other hand, delayed or inappropriately targeted treatments for situations such as fungal infections could have fatal consequences [5]. Considering the complexity of the discussed circumstances, sighting a biochemical marker to lighten a confounding febrile neutropenic episode has came in to the researchers' interest. The acute-phase reactant C-reactive protein (CRP) is 
one of most widely used biochemical inflammatory marker in cancer patients; however, it has a 1-2 days delay to increase after the onset of inflammation and it's serum concentration could be influenced by the underlying malignancy and the grade of tissue damage $[6,8]$. Several macrophage-/monocyte-derived cytokines which mediate a number of metabolic changes known as acute phase reactions have been identified among which interleukin (IL)- 6 seems to be the most important mediator $[9,10]$. IL- 6 is a polypeptide that promptly increases in the early phases of infection due to stimulation by endotoxin, tumor necrosis factor alpha or IL-1, and it may be higher than CRP in early disease and it has a much shorter half-life than CRP $[6,11,13]$. In a budget limited medical setting, CRP is a cheaper and more available diagnostic test comparing with IL-6. However, early detection of patients at risk for fungal infections complications is crucial in decision making about the type and the extent of needed therapy in a febrile neutropenic episode [14].

So we decided to measure serum CRP titer and IL6 level in our oncologic pediatric patients in order to compare the ability of these two mediators in predicting the need for an antifungal drug in order to overcome fever.

\section{Material and Methods}

In this cross-sectional study, all febrile episodes of children aged between 1 to 16 years old who were undergoing anticancer treatment under the care of the pediatric oncology and hematology department at Ali asghar Hospital, between January 2013 and January 2014 were included. Neutropenia was defined as absolute neutrophil count $<1500 / \mathrm{mm}^{3}$ at the time of admission. Fever was documented if axillary temperature was $>38{ }^{\circ} \mathrm{C}$ or $>37.5^{\circ} \mathrm{C}$ for more than 1 hour. Response to the therapy was defined as fever discontinuation within 48 hours of drug initiation.

At the time of admission, samples for Complete blood count (CBC), CRP titer, and IL-6 level were drawn by venepuncture concomitantly with blood culture, prior to administration of antibiotics. The second sample for CBC, CRP titer and IL6 level were repeated on the third day of admission.

Determination of CRP and IL- 6 was based on a quantitative enzymatic immunoassay. Cultures from other sites and radiographs were taken according to clinical Indications.

Finally sensitivity, specificity, positive predictive value and negative predictive in determining the risk of treatment failure were measured.

As a guideline in our department for management of $\mathrm{FN}$, our first line antibacterial therapy included ceftazidime and amikacin, our second line antibacterial therapy included meropenem and vancomycin. If the fever discontinuation would not happen 48 hours after the second line antibacterial therapy, we would add amphotericin B to our patients' regimen.

\section{Statistical Analysis}

Statistical analysis was performed using SPSS version 13 . Mean and standard deviation were calculated for quantitative variables. We used Chi-Square, Fisher and ROC analysis tests. For comparison between the three groups also ANOVA test was used.

\section{Results}

A total of 60 febrile episodes occurring in 49 patients were evaluated. Patient characteristics are summarized in Table 1.

Table 1. Patients characteristics

\begin{tabular}{|c|c|c|}
\hline \multicolumn{2}{|c|}{ Mean age } & 6.45 years \\
\hline \multicolumn{2}{|c|}{ F/M } & $30 / 19$ \\
\hline \multirow{3}{*}{ ANC } & $<500 / \mathrm{mm}^{3}$ & $66.7 \%$ \\
\hline & $500-1000 / \mathrm{mm}^{3}$ & $25 \%$ \\
\hline & $1000-1500 / \mathrm{mm}^{3}$ & $8.3 \%$ \\
\hline \multicolumn{2}{|c|}{ Positive Blood culture } & 6 \\
\hline \multicolumn{2}{|c|}{ Positive Urine culture } & 3 \\
\hline
\end{tabular}

In 31 episodes fever was ceased only by the administration of the first line of antibiotics, while in 17 episodes the discontinuation of fever happened after the administration of the second line of antibiotics. In 12 episodes, fever was discontinued only after the administration of antifungal drugs. The mean level of IL- 6 on the first and the third day of admission were $373.5 \mathrm{pg} / \mathrm{ml}$ and $183.6 \mathrm{pg} / \mathrm{ml}$, respectively. The mean CRP titer on day one was $52.6 \mathrm{mg} / \mathrm{L}$ and on day 3 was $61.5 \mathrm{mg} / \mathrm{L}$. Mean values of IL- 6 level and CRP titer in the three mentioned groups are shown in Table 2 .

Table 2. Median values of IL-6 level and CRP titer in the three groups

\begin{tabular}{|l|l|l|l|l|l|}
\hline Group & & $\begin{array}{l}\text { IL-6 level } \\
\text { on first day }\end{array}$ & $\begin{array}{l}\text { IL-6 level on } \\
\text { third day }\end{array}$ & $\begin{array}{l}\text { CRP titer } \\
\text { on first day }\end{array}$ & $\begin{array}{l}\text { CRP titer on } \\
\text { third day }\end{array}$ \\
\hline $\begin{array}{l}\text { Patients who } \\
\text { responded to first } \\
\text { line of antibiotics }\end{array}$ & Mean & 109.70 & 186.86 & 43.47 & 38.40 \\
\cline { 2 - 6 } $\begin{array}{l}\text { Patients who } \\
\text { responded to } \\
\text { second line of } \\
\text { antibiotics }\end{array}$ & Std Deviation & 148.15 & 909.28 & 39.39 & 38.08 \\
\cline { 2 - 6 } & Std Deviation & 277.81 & 109.70 & 52.41 & 72.97 \\
\hline $\begin{array}{l}\text { Patients who } \\
\text { responded to } \\
\text { antifungals }\end{array}$ & Mean & 1176.30 & 286.50 & 75.81 & 102.26 \\
\cline { 2 - 6 } & Std Deviation & 1962.42 & 351.46 & 44.92 & 66.33 \\
\hline P-value & & $>0.05$ & $>0.05$ & $>0.05$ & 0.001 \\
\hline
\end{tabular}

There was no significant difference between IL- 6 level on first and third day in the three groups $(P>0.05)$. Also there was no significant difference in CRP titer on day one $(P>0.05)$, but CRP titer on the third day was significantly higher in the group who needed to receive antifungal drugs $(P=0.001)$.

Measured levels of IL- 6 and CRP from the day of admission and 48 hours later are presented in figures 1 to 4 .

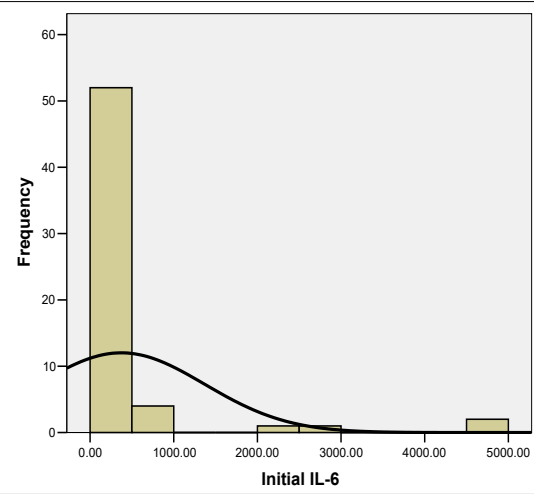

Figure 1. Measured levels of IL-6 in the first day of admission 


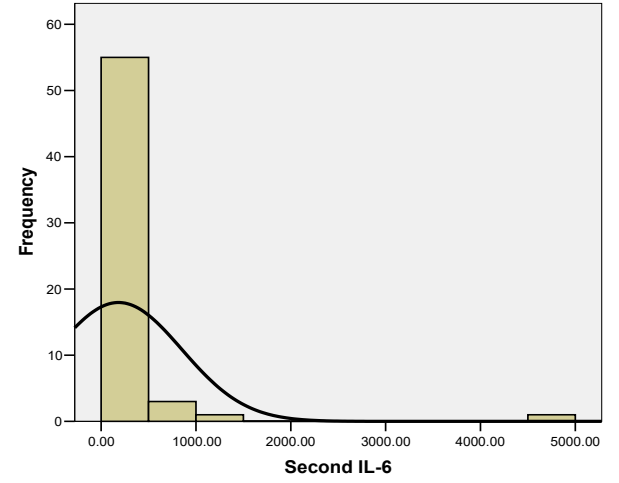

Figure 2. Measured levels of IL- 6 in the third day of admission

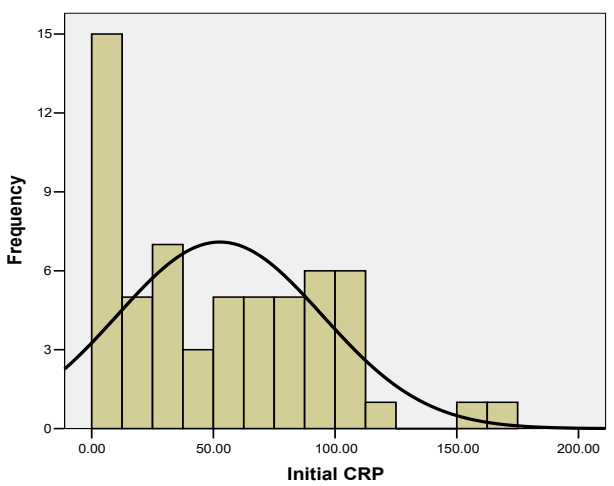

Figure 3. Measured levels of CRP in the first day of admission

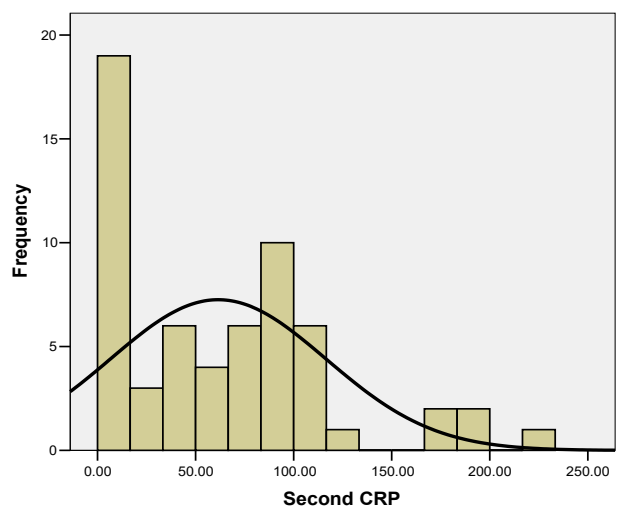

Figure 4. Measured levels of CRP in the third day of admission

Sensitivity, specificity, positive and negative predictive value of IL- 6 level and CRP titer on the first and the third day are summarized in table 3.

Table 3. Sensitivity, specificity, positive and negative predictive value of IL- 6 level and CRP titer on the first and the third day of admission

\begin{tabular}{|l|l|l|l|l|}
\hline & Sensitivity & Specificity & PPV & NPV \\
\hline IL-6 level on the first day & 27.8 & 66.7 & 55.6 & 38.1 \\
\hline IL-6 level on the third day & 41.7 & 58.3 & 60 & 40 \\
\hline CRP titer on the first day & 47.2 & 70.8 & 70.8 & 47.2 \\
\hline CRP titer on the third day & 50 & 75 & 75 & 50 \\
\hline
\end{tabular}

\section{Discussion}

In pediatric patients with febrile neutropenia, there exists a major need for biomarkers which could reflect the severity of infection while being regulated and released independently of the leukocyte count and the activity of the underlying cancer [14]. In a budget limited medical setting with non reliable blood culture results, we evaluated the efficacy of two biomarkers in predicting the need for up leveling the antimicrobial coverage in our pediatric patients with febrile neutropenia. Whether CRP and IL-6 plasma levels have any relevance with fungal infections was the main question that we aimed to answer.

CRP is the most commonly used marker, however, IL-6 is the main stimulator of acute phase proteins such as CRP. Hence, IL-6 level rises more promptly in response to infection followed a few hours later by a rise in CRP titer [15].

Studies have shown that the activity of the underlying malignancy, the chemotherapy-induced tissue damage (such as mucositis) and the severity of cytopenia do not increase CRP and IL-6 plasma levels, considerably [14].

CRP has shown to rise significantly in fungal infections by different research groups $[5,16]$. However, the value of IL-6 known as a rapid responder marker in bacterial infections has not been evaluated in fungal infections. In our study, IL-6, as a more expensive test, did not show any additional diagnostic efficacy comparing with the more available test, CRP.

The potential to tailor therapy according to more sensitive diagnostic tests at the time of admission might permit more judicious use of antimicrobial agents [17]. We suggest that serial monitoring of CRP could help in deciding about the more rapid initiation of antifungal therapy in febrile neutropenic children during chemotherapy. Our results require confirmation in a larger prospective studies and our study was limited by the lack of positive blood cultures and documentation for fungal infections.

\section{Acknowledgments}

We thank the medical and nursing staff of the Hematology and Pediatric Oncology/Haematology units.

\section{Conflict of Interest}

The authors declare having no conflict of interest.

\section{References}

1. Santolaya $M E$, Alvarez $A M$, Aviles CL, Becker A, Mosso $C$ et al. Admission clinical and laboratory factors associated with death in children with cancer during a febrile neutropenic episode. Pediatr Infect Dis J. 2007; 26(9): 794-798. doi: 10.1097/INF.0b013e318124aa44

2. Rackoff WR, Gonin R, Robinson C, Kreissman SG, Breitfeld PB. Predicting the risk of bacteremia in children with fever and neutropenia. J Clin Oncol. 1996; 14(3): 919-924. doi: 10.1200/JCO.1996.14.3.919

3. Talcott JA, Siegel RD, Finberg R, Goldman L. Risk assessment in cancer patients with fever and neutropenia: a prospective, two-center validation of a prediction rule. J Clin Oncol. 1992; 10(2): 316-322. doi: 10.1200/ JCO.1992.10.2.316

4. Kitanovski L, Jazbec J, Hojker S, Derganc M. Diagnostic accuracy of lipopolysaccharide-binding protein for predicting bacteremia/clinical sepsis in children with febrile neutropenia: comparison with interleukin-6, procalcitonin, and C-reactive protein. Supportive Care in Cancer. 2014; 22(1): 269-277. doi: 10.1007/s00520-013-1978-1

5. Marková M, Brodská H, Maličková K, Válková V, Cetkovský P, Kolář M, et al. Substantially elevated C-reactive protein (CRP), together with low levels of procalcitonin (PCT), contributes to diagnosis of fungal infection in immunocompromised patients. Supportive Care in Cancer. 2013; 21(10): 2733-2742. doi: 10.1007/s00520-013-1844-1 
6. Heney D, Lewis IJ, Evans SW, Banks R, Bailey CC, Whicher JT. Interleukin-6 and its relationship to $C$-reactive protein and fever in children with febrile neutropenia. Journal of Infectious Diseases. 1992; 165(5): 886-890.

7. Katz JA, Mustafa MM, Bash RO, Cash JV, Buchanan GR. Value of C-reactive protein determination in the initial diagnostic evaluation of the febrile, neutropenic child with cancer. Pediatric Infectious Disease Journal. 1992; 11(9): 708-712.

8. Santolaya ME, Cofre J, Beresi V. C-reactive protein: a valuable aid for the management of febrile children with cancer and neutropenia. Clin Infect Dis. 1994; 18(4): 589-595.

9. Baggiolini M, Clark Lewis I. Interleukin-8, a chemotactic and inflammatory cytokine. FEBS Letters. 1992; 307(1): 97-101.

10. Bauer J. Interleukin- 6 and its receptor during homeostasis, inflammation, and tumor growth. Klinische Wochenschrift. 1989; 67(14): 697-706.

11. Engervall $P$, Granstrom M, Andersson B, Bjorkholm M. Monitoring of endotoxin, interleukin- 6 and C-reactive protein serum concentrations in neutropenic patients with fever. Eur J Haematol. 1995; 54(4): 226-234.

12. Abrahamsson J, Pahlman M, Mellander L. Interleukin 6, but not tumour necrosis factor-alpha, is a good predictor of severe infection in febrile neutropenic and non-neutropenic children with malignancy. Acta Paediatr. 1997; 86(10): 1059-1064.
13. Engel A, Mack E, Kern P, Kern WV. An analysis of interleukin-8, interleukin-6 and C-reactive protein serum concentrations to predict fever, gramnegative bacteremia and complicated infection in neutropenic cancer patients. Infection. 1998; 26(4): 213-221.

14. Fleischhack G, Kambeck I, Cipic D, Hasan C, Bode U. Procalcitonin in paediatric cancer patients: its diagnostic relevance is superior to that of C-reactive protein, interleukin 6 , interleukin 8 , soluble interleukin 2 receptor and soluble tumour necrosis factor receptor II. British journal of haematology. 2000; 111(4): 1093-1102.

15. Chaudhary N, Kosaraju K, Bhat K, Bairy I, Borker A. Significance of Interleukin-6(IL-6) and C-reactive Protein(CRP) in children and young adults with febrile neutropenia during chemotherapy for cancer: A prospective study. J Pediatr Hematol Oncol. 2012; 34(8): 617-623. doi: 10.1097/MPH.0b013e3182677fc6

16. Roques $\mathrm{M}$, Chretien $\mathrm{ML}$, Favennec $\mathrm{C}$, Lafon I, Ferrant $\mathrm{E}$, Legouge $\mathrm{C}$, et al. Evolution of procalcitonin, C-reactive protein and fibrinogen levels in neutropenic leukaemia patients with invasive pulmonary aspergillosis or mucormycosis. Mycoses. 2016; 59(6): 383-390. doi: 10.1111/myc.12487

17. Lehrnbecher Th, Venzon D, De Haas M, Chanock SJ, Ku“hl J. Assessment of Measuring Circulating Levels of Interleukin-6, Interleukin-8, C-Reactive Protein, Soluble Fcg Receptor Type III, and Mannose-Binding Protein in Febrile Children with Cancer and Neutropenia. Clinical Infectious Diseases. 1999; 29(2): 414-419. doi: 10.1086/520224 